\title{
Effect of Restrictive Infusion on VAP after Colorectal Cancer in Elderly Patients
}

Li Shoushuai, Zheng Chen*

Xi'an Central Hospital, Shaanxi 710003, China

\section{ARTICLE INFO}

Article history:

Published online: 15th July, 2017

Key words:

Restrictive infusion

elderly

colon cancer

ventilator-associated pneumonia

Corresponding author:

Zheng Chen, Xi'an Central Hospital, Shanxi, China. Email: flowerchen_1985@163.com, 13325471009

\section{ABSTRACT}

Objective: To investigate the effect of restrictive infusion on ventilator-associated pneumonia (VAP) in elderly patients with colon cancer treated by operation. Methods: A total of 62 elderly patients underwent colon cancer from January 2015 to March 2016 were randomly divided into study group and control group. The patients in the study group were treated with restrictive rehydration strategy, central venous pressure (CVP) $5 \sim 7 \mathrm{cmH}_{2} \mathrm{O}$, the control group rubbed with conventional rehydration program; the remaining treatment of the two groups of patients to maintain consistency. Results: There was no significant difference in MAP, HR and CO between the study group and the control group at the time of T0 $\sim \mathrm{T} 4(\mathrm{P}>0.05)$. The infusion volume of the study group was significantly lower than that of the control group $(\mathrm{P}(\mathrm{P}<0.05)$. There was no significant difference in the levels of LAC, IL-6 and TNF- $\alpha$ between the two groups $(\mathrm{P}>0.05)$. There was no significant difference in the levels of LAC, IL- 6 and TNF- $\alpha$ between the study group and the control group $(\mathrm{P}<0.05)$. After treatment, the levels of IL- 6 and TNF- $\alpha$ in the study group were significantly lower than those in the control group $(\mathrm{P}<0.05)$. There was no significant difference in the CPIS score between the two groups $(\mathrm{P}>0.05)$. On the $3 \mathrm{rd}$ and 7 th day after operation, the CPSI score of the study group was significantly lower than that of the control group $(\mathrm{P}<0.05)$. Conclusion: The restrictive infusion has no obvious effect on the hemodynamics of elderly patients with colon cancer treated by surgery, but it can reduce the risk of VAP. 


\section{Introduction}

Colon cancer is a common digestive system of malignant tumors, mostly in the elderly population, and a high degree of malignancy, a serious threat to people's lives ${ }^{[1]}$. With the continuous improvement of living standards, the average life expectancy of the elderly continue to extend, the risk of colon cancer is also increasing year by year, to the family and society has brought a great burden ${ }^{[2]}$. At present, the clinical use of surgical methods for elderly patients with colon cancer treatment, the common way for total mesorectal excision, but the laparotomy trauma, bleeding more patients with a variety of complications after surgery High, such as ventilator pneumonia ${ }^{[3]}$. Studies have shown that ${ }^{[4]}$, laparotomy patients with liquid therapy and postoperative respiratory complications have a certain relationship, a large number of input crystal fluid to supplement the blood volume may lead to postoperative cardiovascular and respiratory complications Increased or aggravated, the survival rate of patients was significantly reduced. The restrictive infusion can ensure that blood volume supplement while maintaining the patient's blood pressure at a safe level, can significantly reduce the incidence of postoperative complications of patients ${ }^{[5]}$. In order to further explore the effect of restrictive infusion on postoperative ventilator-associated pneumonia (VAP) in elderly patients with colorectal cancer treated by routine infusion, we used restrictive rehydration strategies and routine rehydration in our elderly patients undergoing colon cancer surgery. The results of the program were analyzed and compared, which provided the theoretical basis for clinical practice.

\section{Materials and methods}

\subsection{General information}

Selected from January 2015 to March 2016 in our hospital colon cancer surgery in 62 cases of elderly patients with random number table method divided into study group and control group of 31 cases.

The study group consisted of 31 patients, 17 males and 14 females, aged 60 to 83 years (mean, $72.1 \pm 8.4$ years). The American Association of Anesthesiologists (ASA) grade: grade 12, grade 19, UICC) stage: 13 cases in stage $\square, 18$ cases in stage $\square$ and $23.7 \pm 2.1 \mathrm{~kg} / \mathrm{m}^{2}$ in body weight index (BMI). The average operation time was $180.4 \pm 22.9 \mathrm{~min}$ and the blood loss was $581.4 \pm$ $83.0 \mathrm{ml}$. The control group was 31 patients, 19 males and 12 females, aged 60 to 81 years, mean $71.3 \pm 7.7$ years, ASA grade: grade $\square 10$ cases, grade 21 cases; UICC staging criteria: 15 cases of stage $\square$, BMI $23.5 \pm$ $1.9 \mathrm{~kg} / \mathrm{m}^{2}$, the average operation time was $183.4 \pm 24.1$ min, and the intraoperative blood loss was $601.3 \pm 91.6$ $\mathrm{ml}$. There was no significant difference in age, sex and ASA grade between the two groups ( $\mathrm{P}>0.05)$.

\subsection{Incorporation criteria}

1.2.1 Inclusion criteria: (1) Colon cancer patients were preoperative pathological biopsy, postoperative pathology confirmed; (2) Age range $\geq 60$ years; (3) ASA grade $\square \sim \square$; (4) Before surgery patients are signed of informed consent.

1.2.2 Exclusion criteria: (1) Preoperative patients with electrolyte imbalance; (2) Patients with coagulation dysfunction, anemia; (3) Preoperative with severe lung disease, pulmonary infection in patients; (4) Patients with other parts of the tumor disease.

\subsection{Rehydration method}

In the study group, the infusion rate was set to $4 \mathrm{ml} / \mathrm{kg}$ $/ \mathrm{h}$, and the central venous pressure was $5-7 \mathrm{cmH}_{2} \mathrm{O}$. The central venous pressure was measured every $15 \mathrm{~min}$. According to the center Venous pressure to adjust the infusion rate, if necessary, can use diuretic drugs, but does not limit the total infusion.

The control group used conventional infusion regimen for infusion, which is total infusion volume $=$ compensatory expansion $(\mathrm{CVE})+$ physiological requirement + cumulative loss + continued loss + third gap loss.

The transfusion crystals of the two groups were selected from lactic acid Ringer's solution, and the colloids were fed with hydroxyethyl starch 1 sodium chloride injection (Wanwen), and the ratio was 2: 1 .

Two groups of patients were taken after the routine rehydration program, while monitoring urine output and hemoglobin, infusion volume according to CVP for 5 $\sim 112 \mathrm{cmH}_{2} \mathrm{O}$ and urine $\geq 0.5 \mathrm{~mL} /(\mathrm{kg} / \mathrm{h})$ to calculate; if the patient in or after surgery of hemoglobin below $100 \mathrm{~g} / \mathrm{L}$, you can enter the concentrated red blood cells.

\subsection{Observation indicators}

The mean arterial pressure (MAP), heart rate (HR) and cardiac output (CO) were measured before and after anesthesia induction (T0), anesthesia for $10 \mathrm{~min}(\mathrm{~T} 1)$, anesthesia for $90 \mathrm{~min}$ (T2) and anesthesia for $180 \mathrm{~min}$ (T3) for any changes; The fluid replenishment and urine volume were recorded and compared between the two groups. Blood lactate (LAC), Interleukin-6 (IL-6), and tumor necrosis factor- $\alpha(\mathrm{TNF}-\alpha)$ levels for preoperative and postoperative $3 \mathrm{~d}$ were recorded

The clinical lung infection score (CPIS) was calculated and monitored by the body temperature, blood routine 
Table 1 Comparison of hemodynamics in both groups $(\overline{\mathrm{x}} \pm \mathrm{s})$

\begin{tabular}{cccccc}
\hline $\begin{array}{c}\text { Observation } \\
\text { indicator }\end{array}$ & Group & T0 & T1 & T2 & T3 \\
\hline $\mathrm{MAP} \square \mathrm{mmHg} \square$ & $\begin{array}{c}\text { Study } \\
\text { group } \\
\text { Control } \\
\text { group }\end{array}$ & $93.3 \pm 11.2$ & $83.3 \pm 12.0$ & $84.0 \pm 11.5$ & $82.6 \pm 12.0$ \\
& $\begin{array}{l}\text { Study } \\
\text { group }\end{array}$ & $75.3 \pm 6.8$ & $74.2 \pm 7.0$ & $73.9 \pm 6.9$ & $74.0 \pm 7.8$ \\
& $\begin{array}{l}\text { Control } \\
\text { group }\end{array}$ & $76.1 \pm 7.4$ & $79.2 \pm 7.7$ & $78.0 \pm 8.1$ & $78.6 \pm 7.4$ \\
\hline
\end{tabular}

index, chest radiography, oxygenation index, airway secretions and sputum culture results on the 1st, 3rd and 7th day after operation.

\subsection{Statistical methods}

The data were analyzed by SAS10.0 software. The mean \pm standard deviation $(\bar{x} \pm s)$ was used. The $t$ test was used between the two groups. $\mathrm{P}$ value $<0.05$ indicates that the difference was statistically significant.

\section{Results}

\subsection{Comparison of hemodynamics between the two groups of patients}

There was no significant difference in MAP, HR and CO between the study group and the control group at the time of $\mathrm{T} 0 \sim \mathrm{T} 4(\mathrm{P}>0.05)$.

\subsection{Two groups of patients with infusion volume and urine volume comparison}

During the operation, the infusion volume of the study group was significantly lower than that of the control group $(\mathrm{P}<0.05)$. There was no significant difference in urine output volume between the two groups $(\mathrm{P}>0.05)$.

\subsection{The two groups of patients with inflammatory factors and LAC comparison}

There was no significant difference in LAC, IL- 6 and TNF- $\alpha$ levels between preoperative, study group and control group $(\mathrm{P}<0.05)$. The levels of IL- 6 and TNF- $\alpha$ in the study group were significantly lower than those in the

Table 2 two groups of patients with infusion volume, urine output $(\overline{\mathrm{x}} \pm \mathrm{s})$

\begin{tabular}{cccc}
\hline Group & $\mathrm{n}$ & Infusion volume $(\mathrm{ml})$ & Urine output volume $(\mathrm{ml})$ \\
\hline Study group & 31 & $1679.2 \pm 341.8$ & $358.1 \pm 66.9$ \\
Control group & 31 & $3264.8 \pm 410.1$ & $370.2 \pm 59.4$ \\
t value & & 16.537 & 0.753 \\
p value & $<0.001$ & 0.491 \\
\hline
\end{tabular}

Table 3 two groups of patients with inflammatory factors, LAC comparison $(\overline{\mathrm{x}} \pm$

\begin{tabular}{|c|c|c|c|c|c|c|c|}
\hline \multirow[b]{2}{*}{ Group } & \multirow[b]{2}{*}{$\mathrm{n}$} & \multicolumn{2}{|c|}{$\mathrm{LAC} \square \mathrm{mmol} / \mathrm{L} \square$} & \multicolumn{2}{|c|}{ TNF- $\alpha \square \mathrm{ng} / \mathrm{L} \square$} & \multicolumn{2}{|c|}{ IL-6 $\square \mathrm{ng} / \mathrm{L} \square$} \\
\hline & & $\begin{array}{c}\text { Before sur- } \\
\text { gery }\end{array}$ & $3 \mathrm{~d}$ after surgery & $\begin{array}{l}\text { Before } \\
\text { surgery }\end{array}$ & $3 \mathrm{~d}$ after surgery & $\begin{array}{c}\text { Before sur- } \\
\text { gery }\end{array}$ & $3 \mathrm{~d}$ after surgery \\
\hline Study group & 31 & $1.3 \pm 0.4$ & $1.4 \pm 0.5$ & $6.3 \pm 2.5$ & $23.1 \pm 3.3 *$ & $78.4 \pm 23.1$ & $201.6 \pm 77.5^{*}$ \\
\hline Control group & 31 & $1.4 \pm 0.4$ & $1.3 \pm 0.6$ & $5.9 \pm 2.6$ & $29.7 \pm 4.1 *$ & $82.0 \pm 29.8$ & $314.2 \pm 82.9 *$ \\
\hline t value & & 0.984 & 0.771 & 0.731 & 8.26 & 0.702 & 4.937 \\
\hline $\mathrm{p}$ value & & 0.351 & 0.486 & 0.498 & $<0.001$ & 0.527 & $<0.001$ \\
\hline
\end{tabular}


Table 4 Comparison of CPIS scores between the two groups ( $\overline{\mathrm{x}} \pm \mathrm{s}$, points)

\begin{tabular}{ccccc}
\hline Group & $\mathrm{n}$ & 1d after surgery & 3d after surgery & 7d after surgery \\
\hline Study group & 31 & $3.67 \pm 0.33$ & $4.50 \pm 0.28$ & $4.11 \pm 0.30$ \\
Control group & 31 & $3.70 \pm 0.31$ & $5.14 \pm 0.30$ & $4.72 \pm 0.35$ \\
t value & & 0.369 & 8.683 & 7.368 \\
p value & 0.629 & $<0.001$ & $<0.001$ \\
\hline
\end{tabular}

control group $(\mathrm{P}<0.05)$.

\subsection{Comparison of CPIS scores between the two groups of patients}

There was no significant difference in CPIS score between the two groups $(\mathrm{P}>0.05)$. On the $3 \mathrm{rd}$ and 7 th day after operation, the CPIS score of the study group was significantly lower than that of the control group $(\mathrm{P}<0.05)$; (Table 4).

\section{Discussion}

With the development of science and technology and medical and health services, human life is constantly extended, the proportion of the elderly is also getting higher and higher, but its body tissues and organs function degenerative changes, the higher the risk of illness ${ }^{[6]}$. Colon cancer is one of the common diseases of the elderly. It mainly refers to the malignant tumor of the digestive tract in the colonic part. The clinical manifestations of cancer patients in the rectum and sigmoid colon are mostly abdominal distension, dyspepsia and bowel habits. Such as anemia, hypothermia, fatigue, weight loss, edema and other symptoms of poisoning, late jaundice, peritoneal effusion, edema and other liver metastases and cachexia, etc., and even lead to Death, a serious threat to people's life and health [7-8].

The current clinical treatment of colon cancer is mainly based on surgical surgery, supplemented by chemotherapy, immunotherapy, traditional Chinese medicine and other treatment, try to improve the surgical resection rate and reduce the recurrence rate, and ultimately improve the survival rate of patients, common surgical approach for total mesorectal excision ${ }^{[9]}$. But the elderly are less tolerant of surgery, especially laparotomy, and perioperative infusion too fast or excessive can cause pulmonary edema and right heart failure, seriously affecting the prognosis of patients. At present, in the course of treatment of elderly patients with colon cancer, the total amount of fluid replacement is the sum of compensatory expansion and cumulative loss, physiological requirement, continuing loss and third gap loss. Promote the expansion of plasma and interstitial fluid, and interstitial fluid can increase the wound, blood loss caused by loss of body fluids, thereby increasing arterial blood pressure and tissue oxygen supply, and can increase intraoperative urine output ${ }^{[10]}$. There are studies have shown that the use of intraoperative plasma can improve intravascular osmotic pressure absorption of interstitial fluid, and further reduce the edema of tissues and organs and improve the body's coagulation function, more conducive to the operation. But excessive infusion during surgery will also cause a certain degree of harm to the patient's heart and lung function, resulting in a variety of heart and lung complications, and patients with postoperative gastrointestinal function recovery and postoperative wound healing caused a certain impact, especially in elderly patients affected by the more obvious ${ }^{[12]}$.

Studies have shown that ${ }^{[13]}$, in elderly patients with colon cancer surgery to limit intraoperative fluid input, maintaining a low central venous pressure and urine output can significantly reduce the incidence of complications, the prognosis is better. Restricted infusion is still not a unified definition, it is not simply to reduce the input of the liquid, but to ensure that the effective circulation of blood and hemodynamics on the basis of the basic stability of the liquid limit and the amount of appropriate input to reduce Complications and mortality. A number of studies have shown that ${ }^{[14-15]}$, restrictive infusion can promote the rehabilitation of patients undergoing elective surgery, and less postoperative complications and bleeding, the patient's surgical results and recovery better.

In order to further explore the effect of restrictive infusion on postoperative ventilator-associated pneumonia (VAP) in elderly patients with colorectal cancer treated by routine infusion, we used restrictive rehydration strategies and routine rehydration in our elderly patients undergoing colon cancer surgery The curative effect of the patients was analyzed and compared, and the hemodynamic indexes, inflammatory factors, LAC and postoperative score were analyzed and compared between the two groups. The results showed that there was no significant difference in MAP, HR and CO between the study group and the control group at the time of T0 $\sim \mathrm{T} 4$, suggesting that the hemodynamics indexes of the two groups were stable and the restrictive infusion was Heart and other important tissues and organs of effective perfusion and oxygenation under 
the premise does not cause the patient's hemodynamic changes. The amount of infusion in the study group was significantly lower than that in the control group. There was no significant difference in the urine volume between the two groups, suggesting that the restrictive infusion could significantly reduce the total infusion while ensuring the completion of the operation. The incidence of complications. At the same time, the levels of IL-6 and TNF- $\alpha$ in the study group were significantly lower than those in the control group, suggesting that restrictive infusion could significantly relieve the stress response and prevent the further development of inflammatory response and restore. The CPIS score of the two groups was not statistically significant at the first day after operation, but the CPSI score of the study group was significantly lower than that of the control group at the 3rd and 7th day postoperatively, suggesting that restrictive infusion could significantly reduce the risk of VAP, The reason may be that restrictive infusion can inhibit the release of inflammatory mediators and the development of inflammatory responses, thereby protecting the lungs and reducing the risk of infection. But there are studies have shown that elderly patients with colon cancer blood is often a high viscosity state, if the rehydration is too small will increase the sticky state, thereby increasing blood flow resistance, leading to heart and brain organ ischemia and hypoxia. However, this study is limited to the lack of research samples, whether the restrictive infusion will affect the patient's blood viscosity still need to do further in-depth study.

In summary, restrictive infusion on the surgical treatment of elderly patients with colon cancer hemodynamic effects are not obvious, but can reduce the risk of VAP patients, it is recommended to further promote the clinical application.

\section{References}

[1] Sears C, Garrett W. Microbes, Microbiota, and Colon Cancer [J]. Cell Host \& Microbe, 2014, 15 (3): 317-328.

[2] Franco S D, Todaro M, Dieli F, et al. Colorectal Cancer Defeating? Challenge Accepted [J]. Molecular Aspects of Medicine, 2014, 39 (6): 61-81.

[3] Han Yu-dong, Song Jingxiang, Lin Chen, et al. Comparison of laparoscopic and open total mesorectalectomy in the treatment of right colon cancer [J]. Chinese Journal of General Surgery, 2014, 29 (1): 17-20.

[4] Zhu Yujun, Chen Gang, Hu Jia, et al. Comparison of Laparoscopic and Open Surgery in the Treatment of Colorectal Cancer and the Complication of Postoperative Complications [J]. Practical Journal of Cancer, 2016,31
(01): 103-106.

[5] Zhao Xin, Xu Kaizhi, Zhang Yonghui. Comparison of Restrictive Infusion and Adequate Fluid Resuscitation in Patients with Septic Shock [J]. Chinese Journal of Nosocomiology, 2014, 24 (2): 411-413.

[6] Anderson J C, Shaw R D. Update on Colon Cancer Screening: Recent Advances and Observations in Colorectal Cancer Screening [J]. Current Gastroenterology Reports, 2014, 16 (16): 1-8.

[7] Steck SE, Butler LM, Keku T, et al. Nucleotide Excision Repair Gene Polymorphisms, Meat Intake and Colon Cancer Risk [J]. Mutation Research / fundamental \& Molecular Mechanisms of Mutagenesis, 2014, 762 (1): 24- 31.

[8] Chen Yuanyuan, Cheng Bo Ran, Wang Zhen, et al. The Detection of Circulating Tumor Cells in Colorectal Cancer in the Application [J]. Chinese Journal of Clinical Medicine: electronic, 2014, 10 (9): 128-132.

[9] Fu Hongjiang. The Latest Progress of Laparoscopic Surgery for Colon Cancer [J]. Medical Review, 2015, 21 (23): 4286-4288.

[10] BAI Li-hong, ZHANG Shu-bo, LIU Tie-jun. Effects Of Target-Oriented Liquid Therapy on Intestinal Barrier of Colon Cancer in Elderly Patients [J]. Journal of Practical Medicine, 2016, 32 (10): 1612-1615.

[11] Lu Huarong, Jiang Jingwei, Zhou Zhaowen, et al. Autologous Blood Transfusion on Acute Brain Surgery and Blood Coagulation Function of the Impact [J]. Chinese Journal of Medicine, 2014, 16 (7): 936-938.

[12] Li Chunyan. Postoperative No Temperature Infusion Nursing on Patients with Open Gallbladder Surgery after Low Temperature and Complications [J]. Hainan Medical, 2015, 26 (19): 2961-2962.

[13] Wei Ke, Wang Zhenglin, He Kaihua, et al. Study on the Application of Controlled Low Central Venous Pressure in Different Types of Hepatectomy [J]. Chinese Journal of Medicine, 2014 (33): 4457-4459.

[14] Liu Yanping, Li Hongjun, Wu Yahui. Efficacy of restrictive infusion in the operation of patients with toxic shock [J]. Chinese Journal of Nosocomiology, 2014,24 (19): 4856-4858.

[15] Meng Jie, Chen Li, Xiao Hang. Effect of Intraoperative Restrictive Infusion on Postoperative Ventilator - Associated Pneumonia in Elderly Patients with Colon Cancer [J]. Journal of Practical Medicine, 2015,31 (17): 28392841. 